\title{
AN EXAMINATION OF FOOTBALL PLAYERS' BELIEFS ABOUT ANTI-DOPING EDUCATION
}

\author{
Andreas LOUKOVITIS ${ }^{1}$, Lida SKOUFA ${ }^{1 *}$, Vassilis BARKOUKIS ${ }^{1}$ \\ ${ }^{1}$ Aristotle University of Thessaloniki, Faculty of Physical Education and Sport Science, Thessaloniki, Greece \\ *Corresponding author: louko-vitis@ hotmail.com
}

https://doi.org/10.35189/dpeskj.2020.59.2.1

\begin{abstract}
The use of doping substances constitutes one of the most significant threats in sport. The present study aimed at examining the beliefs of football players about anti-doping education, as well as their behaviour related to nutritional supplement use and doping use. The sample consisted of 186 football players from sports clubs in Thessaloniki, a city in northern Greece. A self-reported questionnaire, which consisted of five parts, was administered to the football players. The findings revealed limited football players' prior anti-doping education, which was not associated with their age and years of playing football in a club. However, footballers reported that they would be willing to learn about anti-doping. Online education was considered as the most effective way anti-doping education should be offered. Football players indicated behaviour related to nutritional supplement use that was reflective of a neutral stance, while their behaviour related to doping use was reflective of a negative stance. Their age did not differentiate their behaviour towards both nutritional supplement use and doping use. The worrying lack of knowledge about anti-doping among football players underlines the need for relevant education and prevention programmes. This research demonstrates that focusing on footballers' beliefs and behaviours related to doping can provide some knowledge that will be useful in the fight against doping.
\end{abstract}

Keywords: anti-doping education, beliefs, football players.

\section{Introduction}

The use of doping substances constitutes one of the most significant threats in sport as it is against the principles it represents and has been linked to many severe health side effects (Bowers et al., 2009). Morente-Sánchez and Zabala (2013) support in their review that, although this generation of athletes is more aware of anti-doping rules and regulations compared to previous generations, their knowledge about doping continues to be limited. The authors highlighted the need for the development of educational programmes that would provide athletes with valuable information in regard to the use of doping substances, as well as their potential side effects. In addition, they supported that education should not be limited to doping-related issues but should also include information about nutritional supplements and the risk arising from their use.

Numerous studies have attempted to investigate deficits in athletes' awareness of using doping substances (Morente-Sánchez \& Zabala, 2013), but such research is rather limited for football.

A recent study of Spanish football players ranging from elite to under-18 categories has shown that their knowledge of doping is insufficient. More specifically, 97.4\% of athletes were not aware of the Prohibited List published by the World Anti-Doping Agency (WADA), while $94.5 \%$ did not know the significance of the agency itself. This lack of knowledge was apparent across all categories. The authors suggested that this could be very dangerous for 
professional athletes, as the use of a doping substance due to ignorance might cost them their careers. In addition, they highlighted the need for implementing anti-doping education programmes in football. The results of the study also showed that $5 \%$ of the footballers admitted having used a banned substance, while about $1 / 4$ of the sample stated that they knew a person who used a doping substance. (Morente-Sánchez et al., 2019)

Qualitative evidence from elite athletes and other experts involved in sport demonstrated that athletes' confidence in their knowledge about the effects of doping substances was mixed, depending on the substance. Most athletes said that they had used the Internet to seek information about illicit substances, a method that lurks the danger of receiving false information. All participants declared that it would be very beneficial for athletes to receive information about doping substances and suggested that the educational material should be customised to the needs of particular athletes. (Thomas et al., 2011)

A study of Iranian football players and coaches examined their knowledge about dopingrelated issues. The results indicated that athletes had poor knowledge concerning the names of substances, the side effects of anabolic steroids and doping definitions. Participants agreed that the most efficient method of gaining knowledge on this topic would be the implementation of educational programmes. (Barghi et al., 2015)

Another study with amateur footballers showed that $56.4 \%$ of males and $61.2 \%$ of athletes younger than 15 years old could not give a definition of anabolic steroids. Furthermore, half of the sample did not know the side effects of this doping category. (Giraldi et al., 2015)

The issue of lack of knowledge in the use of doping substances was also indicated in a study with junior athletes aged between 14 and 19 years old. The outcomes of the study showed that approximately $40 \%$ of the participants were not aware of WADA's Prohibited List, while roughly $31.4 \%$ of them believed that the substances were banned only for athletes who participated in competitive sport. The most alarming finding was that $20 \%$ of junior athletes were under the impression that athletes would be free to use banned substances if their doctor assented, and about $40 \%$ of them did not know that doping substances were prohibited in sport. In addition, the results showed that there was insufficient knowledge with respect to the side effects of doping substances. (Fürhapter et al., 2013)

Corluka et al. (2011) conducted a research on national football players in three ethnic groups. The results demonstrated that none of the teams managed to reach the average level in a knowledge assessment. Furthermore, $20 \%$ to $30 \%$ of the participants admitted that they would use doping substances if they were sure that the substances would not have any adverse side effects. Importantly, $3 \%$ to $12 \%$ said that they would use such substances regardless of side effects. Based on these results, the authors highlighted the need for tailored anti-doping educational programmes.

A research on athletes involved in individual and team sports investigated their knowledge of doping issues contained in the World Anti-Doping Code. The results indicated that, although only $10 \%$ of the participants acknowledged a lack of knowledge on this topic, more than $80 \%$ were not able to correctly answer questions related to anti-doping regulations and the definition of doping. (Muwonge et al., 2015)

Nevertheless, this lack of knowledge is not limited to doping substances. Waddington et al. (2005) found that one in five football players used nutritional supplements without seeking advice from a professional, while among those who did ask for advice, the doctor 
was the least consulted professional. The researchers suggested that this lack of advice might put athletes at risk of using contaminated supplements, which would result in them being banned. Also, they claimed that the use of supplements, like creatine, might cause adverse health side effects if taken in the wrong dosage.

A study conducted to investigate the use of nutritional supplements in sport showed that the majority of the athletes who used such supplements were not aware of their active ingredient, the way they worked and their potential side effects, while half of them did not know the recommended dosages. Athletes acknowledged that they would like more information on the use of nutritional supplements. (Dascombe et al., 2010)

To sum up, existing evidence suggests that there is a gap in athletes' knowledge about the use of doping substances and nutritional supplements and there is a great need to further investigate these gaps, especially in sports like football where studies are limited, so that researchers can develop and implement effective educational programmes addressing these issues. Furthermore, in order for the educational programmes to be more efficient, it would be beneficial to take into consideration the athletes' views on their content, as well as the way they should be offered. In this regard, the aim of the present study is to examine football players' beliefs about anti-doping education. Moreover, it aims to investigate their behaviour related to both nutritional supplement use and doping use.

\section{Methodology}

\section{Participants}

The sample consisted of 186 football players (182 men and 4 women). Regarding their age, $74.7 \%$ of them were $14-21$ years old, while $25.3 \%$ were over 21 years old. Demographic information captured football players' years of experience in their sport, indicating that most of them (43\%) have played football for 9-11 years. At the time of completing the survey, most football players (48.9\%) reported playing football between 5 and 7 times per week during the season. Participants in this study were recruited from sports clubs in Thessaloniki, a city in northern Greece.

\section{Measure}

A self-reported questionnaire, which consisted of five parts, was administered to the football players. The first part assesses football players' prior anti-doping education. Participants respond in a yes-no format whether they have been offered any education about anti-doping, have attended any lectures regarding anti-doping and are aware of any antidoping training material in their clubs. In the same yes-no format, the second part addresses football players' willingness to receive anti-doping education. The third part is focused on football players' preferred mode of education. Participants indicate their preferences on how anti-doping education should be offered, as well as their preferences on the person who should be responsible for informing athletes about anti-doping issues. Two questions about their preferences on the content of the anti-doping material are included, too. The fourth part of the questionnaire assesses football players' behaviour related to nutritional supplement 
use. It presents a list of the most common legal nutritional supplements, i.e. vitamins and minerals, herbal products, creatine, sports drinks, energy bars, caffeine and proteincarbohydrate shakes. Participants respond whether they have used each of these nutritional supplements in the past 12 months with the intention of improving their performance. The responses to these questions are recorded on a four-point scale ranging from 1 (never) to 4 (frequently). The fifth part of the questionnaire addresses football players' behaviour related to doping use. It presents a list of the most common performance-enhancing substances, i.e. anabolic steroids, beta-blockers, designer steroids, erythropoietin and other similar substances, human growth hormones, diuretics and doping methods. The responses to the questions regarding these substances are recorded on a five-point scale ranging from 1 (never) to 5 (more than 7 times).

\section{Procedure}

The researchers contacted the football clubs, and the aim of the study was described to the club officials. Then, football players were briefed about the aim and procedures of the study. Oral instructions were given to participants regarding the completion of the questionnaire. Participation in the study was voluntary. In addition, football players were reassured that their responses would remain confidential and would be used solely for research purposes. Also, they were encouraged to ask any questions regarding the understanding of the questionnaire items. Completion of the questionnaire lasted approximately 5 minutes.

\section{Data analysis}

The chi-square test for independence was used to assess the association between football players' education about anti-doping and their age, as well the association between football players' education about anti-doping and the years of playing football in a club. In addition, independent-samples t-test analysis was used to assess age-related differences in football players' attitudes towards the use of supplements and performance-enhancing substances. Also, independent-samples t-test analysis was used to test differences in football players' behaviour related to nutritional supplement use and doping use and their willingness to receive anti-doping education. Statistical significance was tested at the .05 level. SPSS 24 Statistical Software was used for statistical analysis.

\section{Results}

\section{Descriptive statistics}

Of the total sample, 182 participants were men and 4 participants were women.

With respect to their participation in a football club, 3.8\% indicated to have played football for 2 years or less, $5.9 \%$ of them to have played football for 3-5 years, $18.8 \%$ to have played football for 6-8 years, and $28.5 \%$ of them to have been engaged with football clubs for 12 years or more. Most of the participants (43\%) reported playing football for 9-11 years. (Figure 1) 


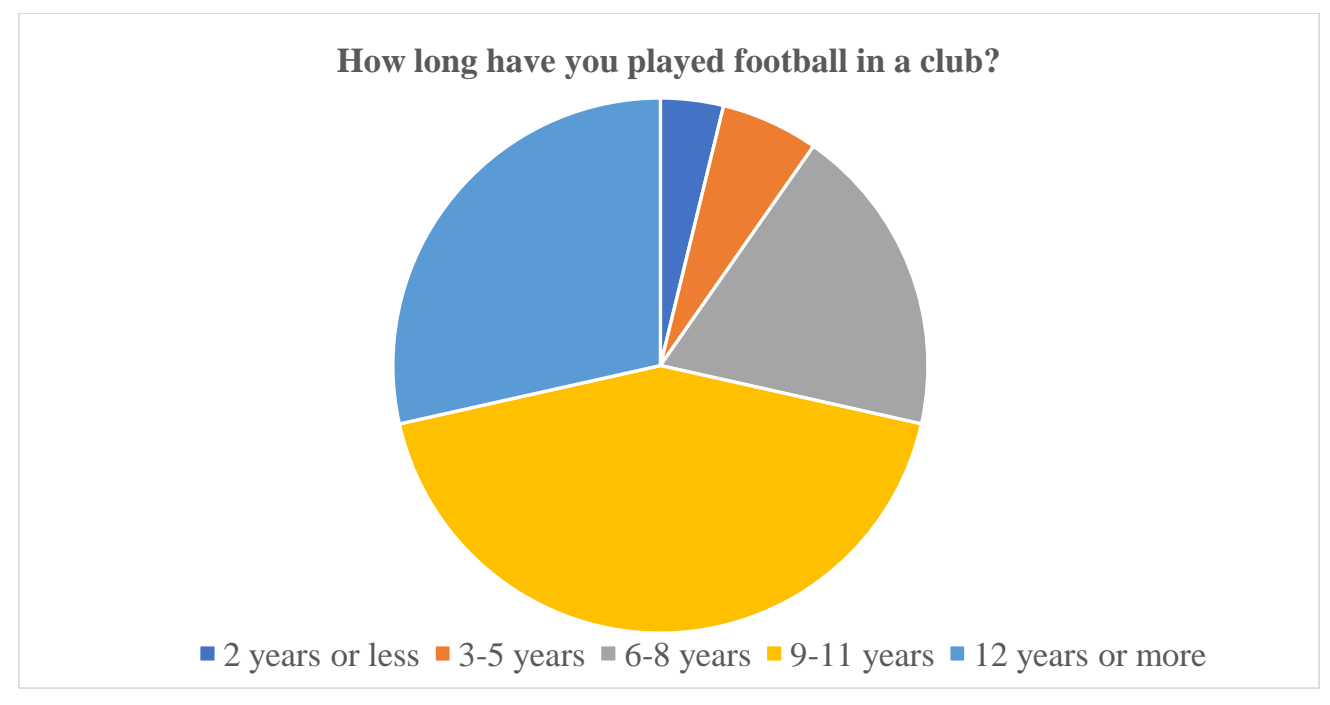

Figure 1. "How long have you played football in a club?"

When asked how many times a week they played football during the season, 9.2\% said 1-2 times, 34.4\% responded 3-4 times per week, and 48.9\%, 5-7 times per week (Figure 2).

How many times do you play football a week during the season?

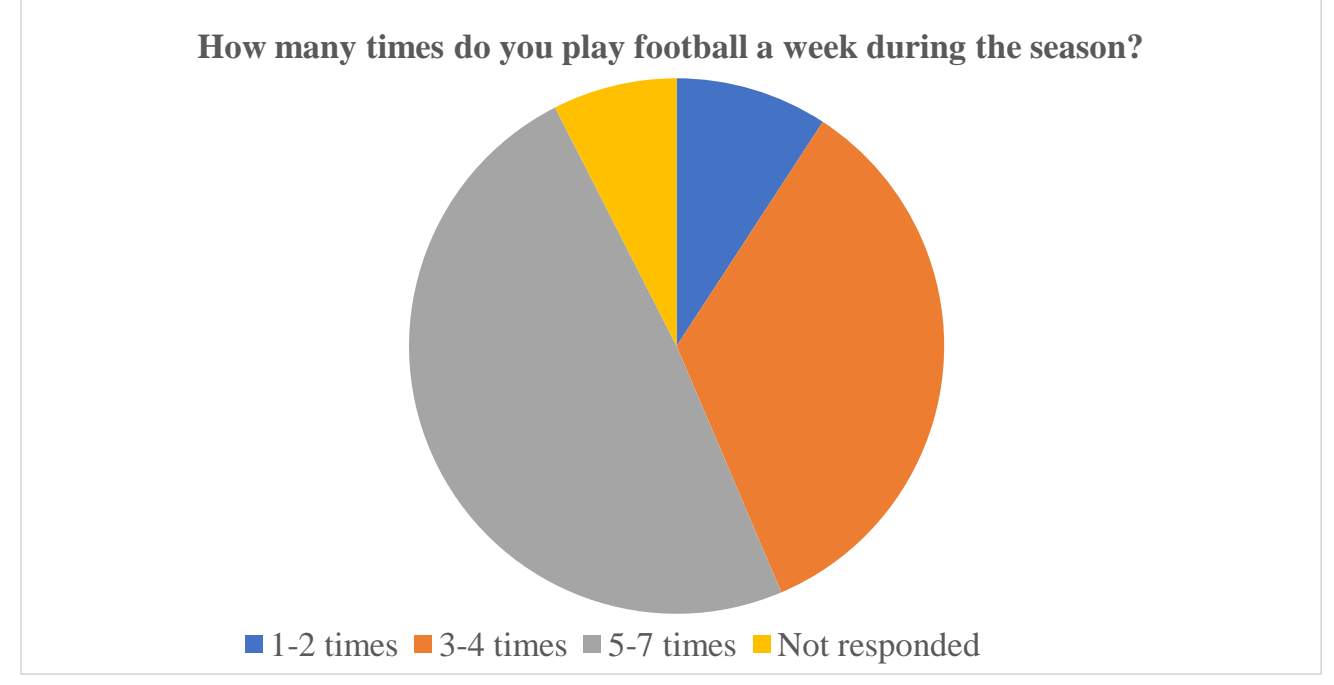

Figure 2. "How many times do you play football a week during the season?"

As for the financial reward due to their involvement in football, the majority of them (69.4\%) earned nothing from playing football. Also, 9.1\% of the participants earned small allowances, $15.6 \%$ of them earned partial salaries, and $5.9 \%$ of them earned full salaries.

In terms of footballers' preferences on the person who should be responsible for informing athletes about anti-doping issues, the athlete was identified by $58.6 \%$ of the participants, the coach was chosen by $32.8 \%$, the management of the club was preferred by $29.6 \%$, the national football federation was chosen by $33.3 \%$, the National Anti-Doping Agency was identified as the key person by $38.2 \%$, the school was chosen by $20.4 \%$, and other person was preferred by $20.4 \%$. 
With respect to footballers' preferences on the content of the anti-doping material, short explanatory videos were chosen by $54.8 \%$ of the participants, PowerPoint presentations were preferred by $30.1 \%$, online tools were identified by $15.6 \%$, case studies of doped athletes were chosen by $40.9 \%$, guidance from clean famous athletes was identified by $30.6 \%$, and $14 \%$ of the footballers chose the booklets.

Finally, regarding footballers' preferences on the topics that should be covered in the antidoping material, anti-doping regulations were chosen by $44.6 \%$ of the participants, doping control procedures were preferred by $30.6 \%$, health side effects of doping were identified as key topics by $60.2 \%$, and moral issues of doping were recognized as important by $29.6 \%$. In addition, trigger points associated with doping were chosen by $30.6 \%$, a topic about how to resist doping offers was indicated by $23.1 \%$, and a topic about how to be informed about legal and prohibited substances was checked by $29.6 \%$. Lastly, a topic about the interplay of nutritional supplements and doping was preferred by $25.8 \%$, a topic about how to support anti-doping policies was indicated by $9.7 \%$, and athletes' rights about doping were chosen by $19.4 \%$.

\section{Football players' education about anti-doping}

Regarding the evaluation of football players' education about anti-doping, the results revealed that 37 footballers had been offered anti-doping education by their clubs, while 149 of them had never been offered any relevant education. The chi-square test for independence showed that there was no statistically significant association between footballers' anti-doping education and their age, $\chi^{2}(3)=4.740, p=.192$. Also, the results indicated that footballers' anti-doping education was not associated with the years of playing football in a club, $\chi^{2}(4)=$ $1.105, p=.894$.

When participants were asked whether they had attended any lectures about anti-doping, the results showed that 61 footballers had attended such lectures, but 125 footballers had not. The chi-square test for independence showed that there was no statistically significant association between attending lectures and footballers' age, $\chi^{2}(3)=7.107, p=.069$. Also, the results indicated that attending lectures was not associated with the years of playing football in a club, $\chi^{2}(4)=2.520, p=.641$.

Regarding the evaluation of football players' awareness of any anti-doping training materials in their clubs, it was found that 29 footballers were aware of anti-doping material, but 157 footballers were not. The chi-square test for independence showed that there was no statistically significant association between footballers' awareness of anti-doping training materials and their age, $\chi^{2}(3)=5.053, p=.168$. Also, the results indicated that footballers' awareness of anti-doping training materials was not associated with the years of playing football in a club, $\chi^{2}(4)=0.749, p=.945$.

When participants were asked whether they would be willing to learn about anti-doping, 115 of them responded positively, 27 responded in the negative, and 42 said they were unsure. The chi-square test for independence showed that there was no statistically significant association between footballers' willingness to learn about anti-doping and their age, $\chi^{2}(6)=$ $8.900, p=.179$. Also, the results indicated that footballers' willingness to learn about antidoping was not associated with the years of playing football in a club, $\chi^{2}(8)=6.083, p=.638$. 
Regarding footballers' preferences on how they would prefer education to be offered, 102 of them chose online education, 60 of them preferred group lessons, and 22 players stated that they preferred reading texts. The chi-square test for independence showed that there was no statistically significant association between footballers' preferences on how anti-doping education was offered and their age, $\chi^{2}(6)=6.456, p=.374$. Also, the results indicated that footballers' preferences on how anti-doping education was offered was not associated with the years of playing football in a club, $\chi^{2}(8)=8.381, p=.397$.

\section{Football players' behaviour related to nutritional supplement use and doping use}

With respect to the football players' behaviour related to nutritional supplement use, this study found that the use of vitamins or minerals in the past 12 months was more frequent in footballers aged over 21 years old $(\mathrm{M}=2.45, \mathrm{SD}=1.17)$ compared to those aged up to 21 years old $(M=2.14, S D=1.10)$, but this difference was not statistically significant, $t(180)=$ $1.596, p=.112$. Also, it was found that the use of herbal products in the past 12 months was more frequent in footballers aged over 21 years old $(\mathrm{M}=1.56, \mathrm{SD}=0.91)$ compared to those aged up to 21 years old $(\mathrm{M}=1.41, \mathrm{SD}=0.78)$, but this difference was not statistically significant, $\mathrm{t}(179)=-1.075, \mathrm{p}=.284$. With regard to the use of creatine in the past 12 months, analysis showed that it was more frequent in footballers aged over 21 years old $(M=1.51$, $\mathrm{SD}=0.88)$ compared to those aged up to 21 years old $(\mathrm{M}=1.23, \mathrm{SD}=0.60)$, but this difference was not statistically significant, $t(54.413)=-1.944, p=.057$.

Regarding the use of sports drinks in the past 12 months, the study found that it was statistically significant more frequently in footballers aged over 21 years old $(\mathrm{M}=2.47, \mathrm{SD}=$ 1.18) compared to those aged up to 21 years old $(\mathrm{M}=1.91, \mathrm{SD}=0.99), t(61.564)=-2.773, p$ $=.007$. In addition, the results showed that the use of energy bars in the past 12 months was more frequent in footballers aged over 21 years old $(\mathrm{M}=2.44, \mathrm{SD}=1.08)$ compared to those aged up to 21 years old $(\mathrm{M}=2.40, \mathrm{SD}=1.07)$, but this difference was not statistically significant, $t(179)=-.231, p=.817$. According to the findings, the use of caffeine in the past 12 months was statistically significant more frequently in footballers aged over 21 years old $(\mathrm{M}=2.91, \mathrm{SD}=1.29)$ compared to those aged up to 21 years old $(\mathrm{M}=2.04, \mathrm{SD}=1.10)$, $t(62.422)=-4.000, p=.000$. Finally, the use of protein-carbohydrate shakes in the past 12 months was more frequent in footballers aged over 21 years old $(\mathrm{M}=2.41, \mathrm{SD}=1.30)$ compared to those aged up to 21 years old $(\mathrm{M}=2.37, \mathrm{SD}=1.27)$, but this difference was not statistically significant, $t(180)=-.179, p=.858$.

In terms of football players' behaviour related to doping use, this study found that the use of anabolic steroids in the past 12 months was more frequent in footballers aged up to 21 years old $(\mathrm{M}=1.01, \mathrm{SD}=0.09)$ compared to those aged over 21 years old $(\mathrm{M}=1.00, \mathrm{SD}=$ $0.00)$, but this difference was not statistically significant, $t(180)=.564, p=.574$. Also, it was found that the use of beta-blockers in the past 12 months was statistically significant more frequently in footballers aged up to 21 years old $(\mathrm{M}=1.09, \mathrm{SD}=0.51)$ compared to those aged over 21 years old $(\mathrm{M}=1.00, \mathrm{SD}=0.00), t(137.000)=2.022, p=.044$. With regard to the use of anabolic steroids in the past 12 months, analysis showed that it was more frequent in footballers aged up to 21 years old $(\mathrm{M}=1.01, \mathrm{SD}=0.12)$ compared to those aged over 21 
years old $(\mathrm{M}=1.00, \mathrm{SD}=0.00)$, but this difference was not statistically significant, $t(178)=$ $.806, p=.421$.

Regarding the use of erythropoietin and other similar substances in the past 12 months, the study found that it was more frequent in footballers aged up to 21 years old $(\mathrm{M}=1.01, \mathrm{SD}=$ 0.12) compared to those aged over 21 years old $(\mathrm{M}=1.00, \mathrm{SD}=0.00)$, but this difference was not statistically significant, $t(180)=.800, p=.425$. In addition, the results showed that the use of human growth hormones in the past 12 months was more frequent in footballers aged up to 21 years old $(\mathrm{M}=1.02, \mathrm{SD}=0.15)$ compared to those aged over 21 years old $(\mathrm{M}$ $=1.00, \mathrm{SD}=0.00)$, but this difference was not statistically significant, $t(136.000)=1.745, p$ $=.083$. According to the findings, the use of diuretics in the past 12 months was more frequent in footballers aged up to 21 years old $(\mathrm{M}=1.03, \mathrm{SD}=0.21)$ compared to those aged over 21 years old $(\mathrm{M}=1.00, \mathrm{SD}=0.00)$, but this difference was not statistically significant, $t(179)=.929, p=.354$. Finally, the use of doping methods in the past 12 months was more frequent in footballers aged up to 21 years old $(\mathrm{M}=1.04, \mathrm{SD}=0.28)$ compared to those aged over 21 years old $(\mathrm{M}=1.00, \mathrm{SD}=0.00)$, but this difference was not statistically significant, $t(179)=.857, p=.393$.

The results on whether football players' willingness to receive anti-doping education differentiated their behaviour related to nutritional supplement use are presented below. In particular, the use of vitamin or mineral supplements in the past 12 months was statistically significant more frequently in footballers who were willing to receive anti-doping education $(\mathrm{M}=2.43, \mathrm{SD}=1.17)$ compared to those who were not $(\mathrm{M}=1.87, \mathrm{SD}=0.96), t(180)=$ $3.351, p=.001$. Also, it was found that the use of herbal products in the past 12 months was more frequent in footballers who were willing to receive anti-doping education $(M=1.50$, $\mathrm{SD}=0.84)$ compared to those who were not $(\mathrm{M}=1.34$, $\mathrm{SD}=0.77)$, but this difference was not statistically significant, $t(179)=1.337, p=.174$. With regard to the use of creatine in the past 12 months, analysis showed that it was more frequent in footballers who were willing to receive anti-doping education $(\mathrm{M}=1.30, \mathrm{SD}=0.65)$ compared to those who were not $(\mathrm{M}=$ $1.29, \mathrm{SD}=0.73)$, but this difference was not statistically significant, $t(128.556)=0.063, p=$ .950 .

Regarding the use of sports drinks in the past 12 months, the study found that it was statistically significant more frequently in footballers who were willing to receive anti-doping education $(\mathrm{M}=2.08, \mathrm{SD}=1.05)$ compared to those who were not $(\mathrm{M}=1.99, \mathrm{SD}=1.09)$, but this difference was not statistically significant, $t(137.927)=0.573, p=.568$. In addition, the results showed that the use of energy bars in the past 12 months was more frequent in footballers who were willing to receive anti-doping education $(\mathrm{M}=2.50, \mathrm{SD}=1.01)$ compared to those who were not $(\mathrm{M}=2.26, \mathrm{SD}=1.15)$, but this difference was not statistically significant, $t(179)=1.411, p=.160$. According to the findings, the use of caffeine in the past 12 months was more frequent in footballers who were willing to receive anti-doping education $(\mathrm{M}=2.36, \mathrm{SD}=1.20)$ compared to those who were not $(\mathrm{M}=2.04, \mathrm{SD}$ $=1.19)$, but this difference was not statistically significant, $t(142.526)=1.738, p=.084$. Finally, the use of protein-carbohydrate shakes in the past 12 months was more frequent in footballers who were willing to receive anti-doping education $(\mathrm{M}=2.46, \mathrm{SD}=1.26)$ compared to those who were not $(\mathrm{M}=2.25, \mathrm{SD}=1.30)$, but this difference was not statistically significant, $t(137.410)=1.049, p=.296$. 
The results on whether football players' willingness to receive anti-doping education differentiated their behaviour related to doping use are presented below. Specifically, the use of anabolic steroids in the past 12 months was more frequent in footballers who were not willing to receive anti-doping education $(\mathrm{M}=1.01, \mathrm{SD}=0.12)$ compared to those who were $(\mathrm{M}=1.00, \mathrm{SD}=0.00)$, but this difference was not statistically significant, $t(180)=-1.297, p$ $=.196$. Also, it was found that the use of beta-blockers in the past 12 months was more frequent in footballers who were not willing to receive anti-doping education $(\mathrm{M}=1.07, \mathrm{SD}$ $=0.50)$ compared to those who were $(\mathrm{M}=1.06, \mathrm{SD}=0.41)$, but this difference was not statistically significant, $t(119.329)=-.170, p=.865$. With regard to the use of designer steroids like tetrahydrogestrinone (THG) in the past 12 months, analysis showed that it was equally frequent in footballers who were not willing to receive anti-doping education and those who were $(\mathrm{M}=1.01, \mathrm{SD}=0.12)$. Regarding the use of erythropoietin and other similar substances in the past 12 months, the study found that it was more frequent in footballers who were not willing to receive anti-doping education $(\mathrm{M}=1.03, \mathrm{SD}=0.17)$ compared to those who were $(\mathrm{M}=1.00, \mathrm{SD}=0.00)$, but this difference was not statistically significant, $t(180)=$ $-1.848, p=.066$.

In addition, the results showed that the use of human growth hormones in the past 12 months was more frequent in footballers who were willing to receive anti-doping education $(\mathrm{M}=1.02, \mathrm{SD}=0.13)$ compared to those who were not $(\mathrm{M}=1.01, \mathrm{SD}=0.12)$, but this difference was not statistically significant, $t(147.057)=.135, p=.893$. According to the findings, the use of diuretics in the past 12 months was more frequent in footballers who were not willing to receive anti-doping education $(\mathrm{M}=1.04, \mathrm{SD}=0.27)$ compared to those who were $(\mathrm{M}=1.01, \mathrm{SD}=0.09)$, but this difference was not statistically significant, $t(179)=$ $1.293, p=.198$. Finally, the use of doping methods in the past 12 months was more frequent in footballers who were willing to receive anti-doping education $(\mathrm{M}=1.04, \mathrm{SD}=0.31)$ compared to those who were not $(\mathrm{M}=1.00, \mathrm{SD}=0.00)$, but this difference was not statistically significant, $t(179)=1.161, p=.247$.

\section{Discussion}

The purpose of this study was to examine football players' beliefs about anti-doping education. A second purpose was to identify football players' behaviour related to nutritional supplement use and doping use. The examination of beliefs and behaviours provides insight into the factors that precipitate nutritional supplement use and may be relevant in explaining doping behaviour. This research provides evidence-based knowledge that can be useful in designing effective anti-doping education programmes.

Overall, the football players in this study indicated limited prior anti-doping education. Most of them reported having never been offered anti-doping education by their clubs and having not attended lectures about anti-doping. Also, the majority of the footballers were not aware of anti-doping material in their clubs. It was observed that footballers' prior antidoping education was associated with neither their age nor the years of playing football in a club. These findings demonstrate an important lack of knowledge about doping. This clearly reinforces the idea of implementing educational anti-doping programmes. The above findings are consistent with previous research that has confirmed gaps in knowledge of doping among 
football players (e.g. Mazanov et al., 2014; Barghi et al., 2015; Morente-Sánchez et al., 2019). For example, Giraldi et al. (2015) found that over 50\% of the football players were not aware of the side effects of doping use.

To extend current understanding of footballers' anti-doping education, their willingness to receive relevant education was examined. Although it is established that players have not received any education, most of them would be willing to learn about anti-doping, indicating their need and desire to be informed. Therefore, it seems that footballers are not responsible for their lack of education in this respect, but it is a fault of the clubs that they do not educate their athletes. It should be noted that footballers' willingness to learn about anti-doping was associated with neither their age nor the years of playing football in a club.

Regarding football players' preferred mode of education, most of them reported that online education was the most effective way anti-doping education should be offered. No significant association was found between footballers' preferences on the way anti-doping education was offered and their age, as well the years of playing football in a club. This finding reflects the modern culture that entails the invasion of the Internet in our lives. Through the Internet, everyone can be informed about everything in a direct way.

As to agents responsible for informing athletes about anti-doping matters, footballers recognised themselves as the main agent of responsibility, while a high percentage of them identified the National Anti-Doping Agency as a key person. This implies that footballers have realised that clubs are not willing to educate them about doping and therefore think that they need to find information on their own. This lack of direct anti-doping education and reliance on self-education is confirmed in previous research (e.g. Posiadala et al., 2009; Johnson et al., 2013). Other studies have demonstrated that several professional figures, such as coaches, are key persons in the education of young athletes about anti-doping (Giraldi et al., 2015).

Furthermore, with respect to footballers' preferences on the content of the anti-doping material, short explanatory videos were chosen by most of the participants. Also, many footballers reported that case studies of doped athletes would be effective. As mentioned above, athletes are familiar with the use of technology and the Internet, and this is the reason why they prefer videos. In addition, well-known athletes who have doped are examples that footballers can identify with. Regarding footballers' preferences on the topics that should be covered in the anti-doping material, health side effects of doping were identified as key topics by the majority of the participants. This finding was anticipated as everyone cares about their health and consequently promoting the negative impact of doping on health can prevent athletes from using such substances. This is confirmed by Strelan and Boeckmann (2006), who reported that health concerns were the strongest predictor of performance-enhancing substance use among athletes.

Another important finding was that the footballers in this study indicated low behaviour towards nutritional supplement use. In particular, participants reported having rarely or sometimes used each of these nutritional supplements in the past 12 months. Among the most common legal nutritional supplements, the use of caffeine in the past 12 months was the most frequent. Maybe this is due to the fact that caffeine is the most used supplement in everyday life. We all usually consume caffeine for energy, alertness and weight loss. Thus, footballers are familiar with the use of caffeine and consider it as an innocent supplement. It should be 
noted that footballers' age did not differentiate their behaviour towards nutritional supplement use. However, the use of sports drinks and caffeine in the past 12 months was statistically significant more frequently in footballers aged over 21 years old compared to those aged up to 21 years old. These findings are consistent with prior research. In their study of young Italian football players, Giraldi et al. (2015) found that only $6.5 \%$ of the footballers admitted using amino acids or creatine during sport activities. In addition, the researchers reported no differences based on footballers' age in relation to the assumption of these substances. However, when comparing the above findings with those of studies focusing on other types of sports, conflicting conclusions emerge. Athletes from different sports reported high frequency of nutritional supplements use. For example, in a study of high-level sailing athletes, more than $77 \%$ admitted using nutritional supplements (Rodek et al., 2012). The inconsistencies between the current study and the studies conducted on athletes participating in other sports may be attributable to different demands of the sport types.

This study also revealed that football players' behaviour related to doping use was reflective of a negative stance. Specifically, participants mostly indicated to have never used doping substances. Perhaps this was due to the fact that the footballers in the present research participated in amateur clubs. The finding is consistent with research on elite Saudi football players, which demonstrated that a small proportion of the players used performanceenhancing substances or thought of using these substances (Al Ghobain, 2019). The fact that doping is an issue that people feel uncomfortable to talk about may explain why small proportions of athletes admit to using doping. The literature has demonstrated that, when questions refer to others' doping use, scores are higher than when participants report their own doping behaviour (Morente-Sánchez \& Zabala, 2015). In addition, the present study found that footballers' age did not differentiate their behaviour towards doping use. However, the use of beta-blockers in the past 12 months was significantly more frequent in footballers aged up to 21 years old compared to those aged over 21 years old. Similarly, in the study by Al Ghobain et al. (2016), higher rates of using doping substances among athletes were associated with being younger than 20 years.

Finally, the study tried to expand knowledge about the relationship between football players' anti-doping education and their related behaviour. The results suggested that football players' willingness to receive anti-doping education did not differentiate their behaviour related to nutritional supplement use. But, surprisingly, the use of vitamin or mineral supplements in the past 12 months was significantly more frequent in footballers who were willing to receive anti-doping education compared to those who were not. Similarly, it was found that football players' willingness to receive anti-doping education did not differentiate their behaviour related to doping use.

\section{Conclusion}

The present study examined the beliefs of football players regarding anti-doping education. In addition, football players' doping behaviour was identified. It has been found that there is limited knowledge about anti-doping. Also, footballers were negative towards doping use. 
The findings from this study emphasise the value of reinforcing education that focuses on doping. The worrying lack of knowledge about anti-doping among football players underlines the need for relevant education and prevention programmes.

This research demonstrates that focusing on footballers' beliefs and behaviours related to doping can provide some knowledge that will be useful in the fight against doping.

\section{Acknowledgement}

This study was conducted with support from the European Commission. This publication reflects only the views of the authors, and the Commission cannot be held responsible for any use which may be made of the information contained therein.

\section{References}

Al Ghobain, M. (2019). Attitudes and behavior related to performance-enhancing substance use among elite Saudi football players. BMC Sports Science, Medicine and Rehabilitation, 11(1): 35. https://dx.doi.org/10.1186\%2Fs13102-019-0149-1

Al Ghobain, M., Konbaz, M. S., Almassad, A., Alsultan, A., Al Shubaili, M., \& AlShabanh, O. (2016). Prevalence, knowledge and attitude of prohibited substances use (doping) among Saudi sport players. Substance Abuse Treatment, Prevention, and Policy, 11(1): 14. https://doi.org/10.1186/s13011-016-0058-1

Barghi, T. S., Halabchi, F., Dvorak, J., \& Hosseinnejad, H. (2015). How the Iranian football coaches and players know about doping? Asian Journal of Sports Medicine, 6(2): e24392. https://dx.doi.org/10.5812/asjsm.6(2)2015.24392

Bowers, L. D., Clark, R. V., \& Shackleton, C. H. (Eds.). (2009). Detection of anabolic steroid abuse in sports. Steroids, 74(3), 285-398. https://www.sciencedirect.com/journal/steroids/vol/74/issue/3

Ćorluka, M., Gabrilo, G., \& Blazevic, M. (2011). Doping factors, knowledge and attitudes among Bosnian and Herzegovinian football players. Kinesiologia Slovenica, 17(3), 49-59. https://www.cabdirect.org/cabdirect/abstract/20123166681

Dascombe, B. J., Karunaratna, M., Cartoon, J., Fergie, B., \& Goodman, C. (2010). Nutritional supplementation habits and perceptions of elite athletes within a state-based sporting institute. Journal of Science and Medicine in Sport, 13(2), 274-280. https://doi.org/10.1016/j.jsams.2009.03.005

Fürhapter, C., Blank, C., Leichtfried, V., Mair-Raggautz, M., Müller, D., \& Schobersberger, W. (2013). Evaluation of West-Austrian junior athletes' knowledge regarding doping in sports. Wiener Klinische Wochenschrift, 125(1-2), 41-49. https://doi.org/10.1007/s00508-012-0318-7

Giraldi, G., Unim, B., Masala, D., Miccoli, S., \& La Torre, G. (2015). Knowledge, attitudes and behaviours on doping and supplements in young football players in Italy. Public Health, 129(7), 1007-1009. https://doi.org/10.1016/j.puhe.2015.05.008

Johnson, J., Butryn, T., \& Masucci, M. A. (2013). A focus group analysis of the US and Canadian female triathletes' knowledge of doping. Sport in Society, 16(5), 654-671. https://doi.org/10.1080/17430437.2012.753522

Mazanov, J., Backhouse, S., Connor, J., Hemphill, D., \& Quirk, F. (2014). Athlete support personnel and anti-doping: Knowledge, attitudes, and ethical stance. Scandinavian Journal of Medicine \& Science in Sports, 24(5), 846-856. https://doi.org/10.1111/sms.12084 
Morente-Sánchez, J., \& Zabala, M. (2013). Doping in sport: A review of elite athletes' attitudes, beliefs, and knowledge. Sports Medicine, 43(6), 395-411. https://doi.org/10.1007/s40279-013-0037-x

Morente-Sánchez, J., \& Zabala, M. (2015). Knowledge, attitudes and beliefs of technical staff towards doping in Spanish football. Journal of Sports Sciences, 33(12), 1267-1275. https://doi.org/10.1080/02640414.2014.999699

Morente-Sánchez, J., Zandonai, T., \& Díaz, M. Z. (2019). Attitudes, beliefs and knowledge related to doping in different categories of football players. Journal of Science and Medicine in Sport, 22(9), 981-986. https://doi.org/10.1016/j.jsams.2019.05.010

Muwonge, H., Zavuga, R., \& Kabenge, P. A. (2015). Doping knowledge, attitudes, and practices of Ugandan athletes: A cross-sectional study. Substance Abuse Treatment, Prevention, and Policy, 10(1): 37. https://doi.org/10.1186/s13011-015-0033-2

Posiadala, D., Smorawinski, J., Pluta, B., \& Andrzejewski, M. (2009). Sport communities and organizations as sources of anti-doping education and places of interest development of students of university school of physical education in Poznan. Studies in Physical Culture \& Tourism, 16(3), 291-299. https://www.wbc.poznan.pl/Content/127563/PDF/8_Posiadala_REV.pdf

Rodek, J., Sekulic, D., \& Kondric, M. (2012). Dietary supplementation and doping-related factors in high-level sailing. Journal of the International Society of Sports Nutrition, 9(1): 51. https://doi.org/10.1186/1550-2783-9-51

Strelan, P., \& Boeckmann, R. J. (2006). Why drug testing in elite sport does not work: Perceptual deterrence theory and the role of personal moral beliefs. Journal of Applied Social Psychology, 36(12), 2909-2934. https://doi.org/10.1111/j.0021-9029.2006.00135.x

Thomas, J. O., Dunn, M., Swift, W., \& Burns, L. (2011). Illicit drug knowledge and information-seeking behaviours among elite athletes. Journal of Science and Medicine in Sport, 14(4), 278-282. https://doi.org/10.1016/j.jsams.2011.02.001

Waddington, I., Malcolm, D., Roderick, M., \& Naik, R. (2005). Drug use in English professional football. British Journal of Sports Medicine, 39(4): e18.

https://doi.org/10.1136/bjsm.2004.012468 